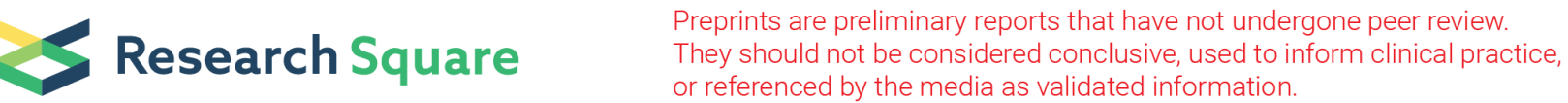

\section{Dimensional Stability and Surface Details Reproduction of Two Extended-Pour Alginate Materials: A Function of Chemical Disinfection and Storage Time. An In- Vitro Study}

\section{Rania A. Sharif}

college of dentistry, king Khalid university, Abha

Khalid M. Abdelaziz

college of dentistry, king khalid university, Abha

Najla Manis Zafer Alshahrani ( $\sim$ dr.najla.alsh@hotmail.com )

college of dentistry, king khalid university, Abha, Saudi arabia https://orcid.org/0000-0003-1408-5255

Fatimah Salem Almutairi

college of dentistry, king khalid university, Abha

Mohrah Awadh Saeed Alaseri

college of dentistry, king khalid university, Abha

Hoda Lotfy Abouzeid

college of dentistry, king khalid university, Abha

Mohamed Fadul A. Elagib

college of dentistry, king khalid university, Abha

Research article

Keywords: Alginate Materials, Chemical Disinfection, Dimensional Stability, Storage Time

Posted Date: July 28th, 2020

DOI: https://doi.org/10.21203/rs.3.rs-41597/v1

License: (c) (i) This work is licensed under a Creative Commons Attribution 4.0 International License.

Read Full License 


\section{Abstract}

Background: Many new extended-pour irreversible hydrocolloid impression materials have been marketed with claims that they demonstrate enhanced surface details accuracy and dimensional stability for up to 120 hours of storage. However, no data in the literature about the effect of storage time on surface details and dimensional stability of extended-pour impression materials upon disinfection. In this study we aimed to evaluate the effect of two chemical disinfection methods and three storage times on dimensional stability and surface details reproduction of 2 extended-pour alginates in comparison with a conventional one.

Methods: A total of 243 alginate impressions were recorded from a custom metal die using Tropicalgin (conventional), Hydrogum5 and Chroma print (extended-pour) alginates. Impressions were categorized into 9 groups according to disinfection method (non-disinfected, sprayed or immersed) and storage time $(0,72,120$ hours). After storage in sealed plastic bag with a damp cotton roll, all impressions were poured with type IV dental stone. The stone models were then examined for surface details and dimensions using a magnifier $(\times 10)$ and digital caliper to assess whether a $25 \mu \mathrm{m}$-line on the metal die was completely reproduced over the full $25 \mathrm{~mm}$ length and its dimensions compared to the original die. Data were analyzed using one-way (ANOVA) and Tuckey's post-hoc test, and KrusKal Wallis test and MannWhitney's test.

Results: With immediate pouring all alginates showed accurate surface details regardless of the disinfection condition, except for immersed Tropicalgin $(P<0.05)$. The extended storage affected surface details of all materials. After $72 \mathrm{~h}$, only non-disinfected extended-pour alginates showed dimensional stability. However, after $120 \mathrm{~h}$ of storage all materials regained dimensional stability except sprayed Tropicalgin.

\section{Conclusions}

Extended-pour alginates hardly proved to be more advantageous than traditional alginate in terms of surface details accuracy. Disinfection methods had some adverse effects on surface details and dimensional accuracy of both extended-pour and conventional alginate. Extended-pour alginate proved dimensional stability after $120 \mathrm{~h}$. It is recommended to immediately pour all alginates whether conventional or extended-pour. Further studies are needed to evaluate impression materials directly to control the confounding variable like gypsum expansion and storage environment in terms of humidity and temperature.

\section{Introduction:}

For obtaining successful dental prostheses, accurate making of impressions and casts of soft and hard oral tissues are necessary. Diagnostic casts are frequently used in dental treatment phases starting from diagnosis and treatment planning phase up to the production of dental restorations, appliances or prostheses [1]. The step of selection of an accurate impression material is therefore critical for optimum 
treatment outcomes biologically, mechanically, functionally and esthetically. In spite of the advances and availability of many types of impression materials, irreversible hydrocolloids are one of the most frequently used in dental fields, due to their low cost and ease of manipulation compared to other materials [2] The main limitation of conventional alginates, however, is their dimensional instability[3] Which is usually related to the physical properties of imbibition (water absorption) and syneresis (water release)[4]. This phenomenon is largely dependent on the condition and length of storage time. Therefore, it is recommended for irreversible hydrocolloids impressions to be poured immediately to prevent distortion [5-7] or within few minutes after removal from the mouth[6]. In some situations; immediate pouring may be not possible especially if the impression is planned to be transferred to a dental laboratory, therefore, to overcome this drawback a new generation of alginates has been introduced to the markets as extended-pour alginates. These new materials are said to have an extended dimensional stability with extended storage time up to 120 hours (h) according to the manufacturer specifications [5, $8,9]$. This could save a lot of dentists' and patients' treatment time. Some available irreversible hydrocolloid alternative products are also marketed and supplied as medium-body addition-type polyvinyl siloxane (PVS)-based materials. According to the manufacturers of products such as AlgiNot FS (Kerr Corp., Romulus, MI) and Position Penta Quick (3M ESPE, St. Paul, MN), it is said that the pouring of impressions may be delayed when needed without any adverse effects on the final result. The manufacturers of these products also claim that impressions may be used for re-pouring of casts [10].

Torassian et al [11] in their study published in 2010 reported that 2 irreversible hydrocolloid alternative materials, AlgiNot FS and Position Penta Quick, were dimensionally stable over an extended period (up to 7 days). Another study showed that 3 irreversible hydrocolloid alternative materials, AlgiNot, Position Penta Quick and Silgimix (Sultan Chemists Inc., Englewood, NJ), underwent dimensional changes that were within the acceptable linear dimensional changes defined by American National Standards Institute/American Dental Association (ANSI/ADA) Specification 19[12]. However, the measurements in that study were made directly from the impressions, rather than from casts poured using the impressions.

\section{- Disinfection of Impression:}

Impressions once removed from the patient's mouth are considered as a cross contamination media. It is recommended to rinse the impression thoroughly with water to get rid of saliva and blood that could be a source of microorganisms, immediately after removal out of the mouth [13]. One recent study concluded that rinsing impressions under water for 15 seconds can eliminate up to $90 \%$ of the cross contamination risks [14]. The current published data recommend that after rinsing impressions, they should undergo a proper disinfection protocol. This can be achieved through spraying or immersion in a chemical disinfectant solution (such as sodium hypochlorite)[15] for variable durations and concentrations as recommended by the manufacturer[16]. It can be done also using alternative methods such as microwave irradiation, exposure to UV light, and autoclave sterilization[17]. This disinfection process can prevent microorganisms from being transferred to dental stone casts[18]. 
Alginates could hold more microorganisms than other impression materials as stated by one study [19]. This why some published data suggest the use of self-disinfecting alginates by incorporating silver nanoparticles [20] in the hydrocolloid powder or by mixing the conventional powder with chlorhexidine [21] for a more convenient and practical disinfection of alginate impression materials used in dental practice. Disinfection of alginate impressions through immersion in disinfectant solutions were reported to be more effective, [22-24] however, spraying impressions with disinfectant solutions showed less dimensional changes of resulting casts.[25, 26].

Although various recent studies included extended-storage alginate materials, [27-29] these investigations evaluated impression dimensional change over time without evaluating the effect of disinfection materials and techniques on dimensional stability and surface details reproduction. Therefore, this study aimed at evaluating the effect of storage time and disinfection conditions on dimensional stability and surface details reproduction of two extended-pour alginate brands in comparison with a conventional one.

The objective of this study was to test and compare the effects of chemical disinfectants and storage time on a conventional irreversible hydrocolloid and two extended-pour impression materials with regard to the parameters of surface details reproduction and dimensional stability.

\section{Methods:}

This in-vitro study was designed and conducted in the Department of Prosthodontics, College of Dentistry, King Khalid University, Abha, KSA during 2019. Ethical approval was obtained from the scientific research committee of College of Dentistry, King Khalid University with a registration number SRC/ETH/20, 17-/18/52.

\section{Test Materials:}

\section{Impression Materials:}

Three commercially available hydrocolloids were selected namely, Hydrogum 5, Chroma print (extended pour alginates) and Tropicalgin (conventional alginate). These materials were evaluated by testing dimensional stability and surface details reproduction accuracy of their produced master casts. A die was prepared for the impression making procedures.

\section{(Fig. 1)}

\section{Figure 1}

Different Alginate Impression Materials

\section{Dental Stone:}

Type IV dental stone was used to pour the alginate impressions. 
Different materials used in the test are illustrated in Table 1.

Table 1

Different Test Materials

\begin{tabular}{|lll|}
\hline Test materials & Manufacturer & Material Type \\
\hline Hydrogum 5 & Zhermak & Irreversible Hydrocolloid (Extended pour time) \\
\hline Chroma print & Coltene & Irreversible Hydrocolloid (Extended Pour time) \\
\hline Tropicalgin & Zhermak & Irreversible Hydrocolloid (Conventional) \\
\hline Durone IV & Dentsply & Type IV Dental Stone \\
\hline 3. Custom Stainless Steel Die: & \\
\hline
\end{tabular}

Impressions using the three alginate materials were prepared over a custom-made metal die $(300 \mathrm{~mm}$ outer diameter and $270 \mathrm{~mm}$ internal diameter). The die includes three parallel lines 25,50 , and $75 \mu \mathrm{m}$ wide and $25 \mathrm{~mm}$ in length and spaced $2.5 \mathrm{~mm}$ apart, with two lines intersecting the three lines to determine the dimensional accuracy and surface detail reproduction on the $25 \mu \mathrm{m}$ line. (Fig. 2)

\section{Figure 2}

Custom stinless steel die used for making impression

- Test Procedures:

Impression and disinfection Procedures:

The impression trays used were custom-made perforated metal trays which fit to the die with a uniform thickness space. After mixing the impression materials according to the manufacturer's instructions, they were loaded in the trays and joined to the die and pressed using a $1 \mathrm{~kg}$ weight to allow excess material to escape, until completion of setting time. The tests were performed in accordance with the American National Standards Institute/ American Dental Association (ANSI/ADA) Specifications Nos. 18 and 19.

(Figs. 3, 4, 5)

\section{Figure 3}

custom-made perforated metal tray

\section{Figure 4}

A $1 \mathrm{~kg}$ weight placed over the tray to allow even pressure

\section{Figure 5}

Completed impression 
The trays then were removed 1 minute after gelation (the gelation time was consistent with the minimum time recommended by the manufacturers) and then disinfected either by:

1) No treatment with disinfectant solution (as control group).

2) Spraying with $5.25 \%$ sodium hypochlorite disinfectant as recommended in manufacturer's instructions.

2) Immersion in $2 \%$ glutaraldehyde for 10 minutes as recommended in manufacturer's instructions.

\section{Storage of Impressions:}

All disinfected and control impressions were rinsed under tap water for 10 seconds then stored in a sealed plastic bag with a damp cotton roll (to ensure a relative humidity) at the room temperature for the storage periods of 0,72 or 120 hours (h). (Figs. 6,7 )

\section{Figure 6}

A group of stored impression samples

Figure: 7: A group of poured casts

- Under standardized conditions, a total of 243 alginate impressions were recorded and divided into 27 experimental groups (9 impressions in each group). Table 2 shows the different experimental groups of the study. 
Table 2

Experimental groups

\begin{tabular}{|c|c|c|c|c|}
\hline \multirow[t]{3}{*}{ Disinfection method } & \multirow{3}{*}{$\begin{array}{l}\text { Storage } \\
\text { time }\end{array}$} & \multicolumn{3}{|c|}{ Experimental groups } \\
\hline & & \multicolumn{3}{|c|}{ Alginate impression material (Brand) } \\
\hline & & $\begin{array}{l}\text { Hydrogum } 5 \\
\text { (Extended pour) }\end{array}$ & $\begin{array}{l}\text { Chroma print } \\
\text { (Extended pour) }\end{array}$ & $\begin{array}{l}\text { Tropicalgin } \\
\text { (conventional) }\end{array}$ \\
\hline \multirow[t]{3}{*}{ No disinfection } & Immediate & Group 1 & Group 2 & Group 3 \\
\hline & 72 hours & Group 4 & Group 5 & Group 6 \\
\hline & 120 hours & Group 7 & Group 8 & Group 9 \\
\hline \multirow{3}{*}{$\begin{array}{l}\text { Spraying (5.25\% } \\
\text { NaOCL) }\end{array}$} & Immediate & Group 10 & Group 11 & Group 12 \\
\hline & 72 hours & Group 13 & Group 14 & Group 15 \\
\hline & 120 hours & Group 16 & Group 17 & Group 18 \\
\hline \multirow{3}{*}{$\begin{array}{l}\text { Immersion (2\% } \\
\text { Gluteraldehyde) }\end{array}$} & Immediate & Group 19 & Group 20 & Group 21 \\
\hline & 72 hours & Group 22 & Group 23 & Group 24 \\
\hline & 120 hours & Group 25 & Group 26 & Group 27 \\
\hline
\end{tabular}

\section{Casting Procedure:}

After the specified storage periods, impressions were immediately poured with type IV dental stone to generate casts. After one hour of mixing stone, the casts were separated from the molds and permitted to dry for 24 hours.

\section{Assessments:}

- Assessment of Surface Details Reproduction:

- Evaluations were performed on the stone casts using a ( $\times 10)$ magnifying lens to assess the $25 \mu \mathrm{m}$ line, whether it was reproduced completely through its full length in the casts. The procedure was repeated three-times for each cast and the results were recorded on a scale of 1 to 4 as proposed by Owen in 1986.[30]

- Assessment of Dimensional Stability:

- On The stone cast, the $25 \mu \mathrm{m}$ - line was measured for dimensional changes compared to the original dimensions of the stainless steel die using an electronic digital caliper. (Fig. 8) The measurement procedure was repeated 3 times for each cast.

\section{Figure 8}

Electronic digital caliper used for measuring the dimensional changes. 


\section{Statistical Analysis:}

- Means and standard deviations were calculated for each experimental group. A one-way analysis of variance (ANOVA) was used to assess the effects of each of material brand, disinfection technique, and storage time on the dimensional stability, followed by a Tuckey's post-hoc test among groups. Moreover, for evaluating the surface details reproduction, KrusKal Wallis test was used followed by Mann-Whitney's test. The level of significance was predetermined at $P \leq 0.05$.

- Data was statistically analyzed using SPSS version 24 software (SPSS Inc., Chicago, IL, USA).

\section{Results:}

\section{Dimensional Stability:}

The differences on measurements obtained from directly measuring the surface of the custom stainlesssteel die and the mean and standard deviation measurements of casts poured from the three impression materials at the different disinfection conditions and each time interval are shown in Table 3.

Table 3

Dimensional Change of casts poured from three irreversible hydrocolloids at different storage times and disinfection conditions

\begin{tabular}{|c|c|c|c|c|}
\hline & & Immediate Pouring & 72 hours storage & 120 Hours Storage \\
\hline Brand & $\begin{array}{l}\text { Disinfection } \\
\text { Method }\end{array}$ & $\begin{array}{l}\text { Dimensional } \\
\text { Changes }(\mathrm{mm}) \text { Mean } \\
\pm \text { SD }\end{array}$ & $\begin{array}{l}\text { Dimensional } \\
\text { Changes }(\mathrm{mm}) \text { Mean } \\
\pm \text { SD }\end{array}$ & $\begin{array}{l}\text { Dimensional } \\
\text { Changes }(\mathrm{mm}) \text { Mean } \\
\pm \text { SD }\end{array}$ \\
\hline \multirow[t]{3}{*}{ Hydrogum } & No & $0.01 \pm 0.06$ & $0.01 \pm 0.06$ & $0.15 \pm 0.13$ * \\
\hline & Spray & $0.06 \pm 0.12$ & $0.23 \pm 0.13$ * & $0.10 \pm 0.06$ \\
\hline & Immersion & $0.05 \pm 0.14$ & $-0.02 \pm 0.04$ * & $0.12 \pm 0.09$ \\
\hline \multirow{3}{*}{$\begin{array}{l}\text { Chroma } \\
\text { Print }\end{array}$} & No & $0.09 \pm 0.04$ & $0.05 \pm 0.13$ & $0.04 \pm 0.04$ \\
\hline & Spray & $0.07 \pm 0.02$ & $0.07 \pm 0.17$ & $0.14 \pm 0.12$ \\
\hline & Immersion & $0.08 \pm 0.11$ & $-0.02 \pm 0.19 *$ & $0.05 \pm 0.08$ \\
\hline \multirow[t]{3}{*}{ Tropicalgin } & No & $0.02 \pm 0.11$ & $-0.05 \pm 0.24$ * & $0.01 \pm 0.13$ \\
\hline & Spray & $-0.04 \pm 0.09$ & $0.1 \pm 0.1$ * & $-0.03 \pm 0.08 *$ \\
\hline & Immersion & $0.01 \pm 0.1$ & $0.01 \pm 0.08$ * & $0.08 \pm 0.22$ \\
\hline
\end{tabular}

- Positive values indicate expansion in impressions \& negative values indicate contraction in impressions

- *: statistically significant difference $(\mathrm{P}($ same) $)$ 
All casts either expanded or contracted in size compared to the direct measurements of the custom die, with a general trend towards expansion. The mean dimensional change ranged between $(-0.01 \mathrm{~mm}$ and + $0.23) \mathrm{mm}$. The greatest change was recorded by Hydrogum ${ }^{\circledR}$ (an extended pour alginate) and the least change was recorded by Hydrogum ${ }^{\circledR}$ and Tropicalgin ${ }^{\circledR}$ (conventional alginate). (Figure.9)

\section{Figure 9}

Dimensional Change of casts made from the 3 impression materials with different disinfection conditions and storage time intervals

\section{Surface Detail Reproduction:}

- Casts poured with or without disinfection of the three impression materials at different storage periods showed variable scores of surface detail reproduction which ranged between 1 and 3 .

- The casts that showed greatest and least accuracy in production of the $25 \mu \mathrm{m}$-line through its full length were both poured after 5 days of storage of impression. The casts of least accuracy were poured from immersed Hydrogum specimens, while the most accurate were poured from sprayed Chroma Print specimens. (Fig. 10)

Figure 10: surface detail reproduction of all casts

\section{Results According to the Impression Material:}

\section{Dimensional Stability:}

Statistical analysis of the dimensional changes between the original die and casts poured from each material showed the following:

- No significant statistical differences between the mean measurements regardless of storage time and disinfection method for both Chroma print and tropicalgin poured samples. (Figs. 11, 12)

\section{Figure 11}

dimensional change of Tropicalgin

\section{Figure 12}

dimensional change of Chroma Print

- Hydrogum 5 poured samples showed significant differences at 72 hours of storage time, when disinfected with either spraying or immersion. Also samples which were not disinfected and poured at 120 hours of storage showed significant differences. (Fig. 13)

Figure 13: dimensional change of Hydrogum 5 


\section{Surface Details Reproduction:}

Statistical analysis of the surface details reproduction between the original die and casts poured from each material showed the following:

- Hydrogum: All samples poured from Hydrogum material showed significant difference compared to original die, regardless of storage time and disinfection method. (Fig. 14)

\section{Figure 14}

surface detail reproduction of Hydrogum 5

- Both Chroma print and tropicalgin: All samples poured at 120 hours of storage showed significant differences, also those disinfected with either spraying or immersion and poured at 72 hours.

(Figs. 15, 16)

\section{Figure 15}

surface detail reproduction of chroma print

\section{Figure 16}

surface detail reproduction of Tropicalgin

Results According to the Storage -Time:

Immediately poured casts:

- All three materials, showed no significant differences in terms of both dimensional stability and surface details reproduction regardless of disinfection condition $(P>0.05)$, except for the immersed Tropicalgin which had a decrease in the accuracy of surface details reproduction $(P<0.05)$. (

Figs. 17, 18)

\section{Figure 17}

dimensional changes on immediate pouring

Figure 18: surface detail reproduction on immediate pouring

\section{After 72 hours of storage:}

- Surface details reproduction of all the three materials had significant changes $(P<0.05)$. (Fig. 19)

\section{Figure 19}

surface detail reproduction after 72 hours 
- All casts poured from the three materials samples had significant dimensional changes $(P<0.05)$, except for non-disinfected Hydrogum 5 and Chroma print (extended pour alginate) poured casts.

(Fig. 20)

\section{Figure 20}

dimensional changes after 72 hours of storage

\section{After 120 hours of storage:}

- All casts had significant changes in surface details reproduction compared to the original die. (

Fig. 21)

\section{Figure 21}

surface detail reproduction after 5 days

- Only sprayed Tropicalgin poured casts showed significant dimensional instability $(P<0.05)$. (Fig. 22)

\section{Figure 22}

dimensional change after 5 days of storage

\section{Figure 23}

dimensional change of all casts at different storage time intervals

\section{Discussion:}

In this study two chemical disinfectants were used namely, NaOCl Sodium hypochlorite $5.25 \%$ solution (Spray) and Gluteraldehyde 2\% (Immersion). Each of these agents has been considered as an effective disinfection media for irreversible hydrocolloids impression materials without significant effects on them when used according to the manufacturer's instructions. This technique is widely used and adopted by many authors. [31-33]

In order to eliminate operator fatigue and bias, assessment procedures of surface detail reproduction and dimensional changes of each cast have been performed by three operators and the mean measurements and scores were considered.

In this study three commercially available hydrocolloids tested and showed different results, which reflected that dimensional stability of the impression related to the type of material used, storage time interval, and disinfection conditions. Therefore, the null hypothesis," The brand of extended-pour alginate, storage time intervals, disinfection and conditions do not affect the dimensional accuracy or surface details reproduction of extended pour alginate impression materials and therefore their generated stone casts." is rejected. 


\section{Dimensional Stability}

All casts either expanded or contacted in size compared to the direct measurements of the custom die, with a general trend towards expansion. The mean dimensional change ranged between $-0.05 \mathrm{~mm}$ and $0.23 \mathrm{~mm}$. This is more than the results reported by Usama Nassar et al. 2012 who reported between $0.02 \mathrm{~mm}$ and 0.05 dimensional changes. This is because the maximum delay in pouring time in their study was 4 hours, while in our present study it was 120 hours. This may indicate that the longer the delays in pouring time the more dimensional changes are expected [31-33]. So, the prolonged storage time is not advised as stated by many published data [18-22,32]

The maximum change was recorded by Hydrogum ${ }^{\circledR}$ and the least change was recorded by Tropicalgin $\circledast$. This is in contrast with the results reported by Sedda M. et al 2008 who stated that in all the tested measurements. After 24 hours of storage, only Alginoplast and Hydrogum 5 fit all the measurements $(p>$ 0.05) [31-33].

After $72 \mathrm{~h}$, only non-disinfected extended-pour alginates showed dimensional stability. However, after $120 \mathrm{~h}$ of storage all materials regained dimensional stability except sprayed Tropicalgin ${ }^{\circ}$.

Surface details reproduction with immediate pouring all alginates showed accurate surface details regardless disinfection method, except for immersed Tropicalgin. $(P<0.05)$ while the extended storage affected surface details of all materials.

Immediately poured casts All three materials, showed no significant differences in dimensional stability and surface details reproduction regardless of disinfection condition $(P>0.05)$, except for the immersed Tropicalgin which had a decrease in the surface details reproduction $(P<0.05)$.

After $\mathbf{7 2}$ hours of storage Surface details reproduction of all the three materials had significant changes $(P<0.05)$. All casts poured from Tropicalgin samples had significant dimensional changes. Hydrogum and Chroma print (Extended pour alginate) poured casts were dimensionally different after being disinfected. $(P<0.05)$.

After 120 hours of storage all casts had significant changes in surface details reproduction compared to original die. Only sprayed Tropicalgin poured casts showed significant dimensional instability $(\mathrm{P}<$ 0.05).This is in contrast with the results reported by Sedda M. et al 2008 who stated that the only casts able to comply with the control group in all the measurements after 72 and 120 hours were obtained from Hydrogum $5(p>0.05)$ [31-33].

\section{Conclusions:}

With the limitations of this in vitro studies the following conclusions could be mentioned:

1. The extended pour impression materials hardly proved to be more advantageous than traditional irreversible hydrocolloid materials in terms of surface details accuracy. 
2. Disinfection with spraying or immersion had adverse effects on surface details and dimensional accuracy of both extended-pour and conventional alginate, especially after 72 hours of storage.

3. After 120 hours of storage, although extended pour alginate brands had good dimensional stability, they had a decrease in surface details accuracy.

4. It is recommended to pour all irreversible hydrocolloids materials immediately whether conventional or extended-pour.

5. Further in vitro studies are needed to evaluate the impression materials directly without the confounding variable of gypsum expansion and with more consistent storage environment of humidity and temperature.

\section{Study Limitations:}

1. 1. Although in this study the standardized protocols for impression making were followed, results in vivo may differ because of the oral fluids and microorganisms.

2. 2. Storage temperature and humidity conditions might be standardized by using incubators with a certain preset temperature and humidity conditions.

3. 3. The assessment of parameters of surface details reproduction and dimensional stability were performed on dental stone casts poured from the impression materials instead of performing them directly in the different impression material specimens.

\section{Declarations}

Acknowledgements: Not applicable.

Declarations: The authors have no conflict of interest with the companies whose materials were mentioned in present study.

Ethics approval and consent to participate: Not applicable.

Consent for publication: Not applicable.

Competing interests: Not applicable.

Funding: It is a self-funded project by the authors.

\section{Authors' contributions:}

RAS developed the research idea, research design, supervised data collection and revised the results. KMA finalized the research idea, Sample's mold design, performed the statistical analysis and interpreted the results. NMZ, FSA and MAS prepared the test materials and all test samples (making Impressions, disinfection procedure, storage of samples, and pouring casts), determined the study results.

HLA and MFA tested the materials and wrote the manuscript with the rest of the authors. All authors had read and approved the final manuscript. 
Availability and sources of materials: Appendix A

\section{References}

1. Sivakumar A, Thangaswamy V, Ravi V. Treatment planning in conservative dentistry. Journal of pharmacy bioallied sciences. 2012;4(Suppl 2):406-9.

2. Arqoub M, Rabi T, Arandi N. Dental impression materials in prosthodontics: An overview for the general dentist. International Journal of Preventive Clinical Dental Research. 2018;5(3):21-3.

3. Kulkarni MM, Thombare RU. Dimensional Changes of Alginate Dental Impression Materials-An Invitro Study. Journal of clinical diagnostic research: JCDR. 2015;9(8):Zc98-zc102.

4. Sacher EAF. Rodrigo. Dental Biomaterials.

5. Sedda M, Casarotto A, Raustia A, Borracchini A. Effect of storage time on the accuracy of casts made from different irreversible hydrocolloids. J Contemp Dent Pract. 2008;9(4):59-66.

6. Cohen BI, Pagnillo M, Deutsch AS, Musikant BL. Dimensional accuracy of three different alginate impression materials. J Prosthodont. 1995;4(3):195-9.

7. Donovan TE, Chee WW. A review of contemporary impression materials and techniques. Dent Clin North Am. 2004;48(2):vi-vii. 445 - 70.

8. Walker MP, Burckhard J, Mitts DA, Williams KB. Dimensional change over time of extended-storage alginate impression materials. Angle Orthod. 2010;80(6):1110-5.

9. Alcan T, Ceylanoglu C, Baysal B. The relationship between digital model accuracy and timedependent deformation of alginate impressions. Angle Orthod. 2009;79(1):30-6.

10. Nassar U, Hussein B, Oko A, Carey JP, Flores-Mir C. Dimensional accuracy of 2 irreversible hydrocolloid alternative impression materials with immediate and delayed pouring. J Can Dent Assoc. 2012;78:c2.

11. Torassian G, Kau CH, English JD, Powers J, Bussa HI, Marie Salas-Lopez A, et al. Digital models vs plaster models using alginate and alginate substitute materials. Angle Orthod. 2010;80(4):474-81.

12. Patel RD, Kattadiyil MT, Goodacre CJ, Winer MS. An in vitro investigation into the physical properties of irreversible hydrocolloid alternatives. J Prosthet Dent. 2010;104(5):325-32.

13. Hatrick WSEC. Clinical Applications for Dental Assistants and Dental Hygienist: Saunders; 3rd March 2015.

14. McNeill MR, Coulter WA, Hussey DL. Disinfection of irreversible hydrocolloid impressions: a comparative study. Int J Prosthodont. 1992;5(6):563-7.

15. Babiker GH, Khalifa N, Alhajj MN. Dimensional Accuracy of Alginate Impressions Using Different Methods of Disinfection With Varying Concentrations. Compend Contin Educ Dent. 2018;39(1):e1720.

16. Mushtaq MAKM. An overview of dental impression disinfection techniques- a literature review. J Pak Dent Assoc. 2018;27(4):207-12. 
17. AlZain S. Effect of chemical, microwave irradiation, steam autoclave, ultraviolet light radiation, ozone and electrolyzed oxidizing water disinfection on properties of impression materials: A systematic review and meta-analysis study. The Saudi Dental Journal. 2020;32(4):161-70.

18. Leung RL, Schonfeld SE. Gypsum casts as a potential source of microbial cross-contamination. J Prosthet Dent. 1983;49(2):210-1.

19. Al-Jabrah O, Al-Shumailan Y, Al-Rashdan M. Antimicrobial effect of 4 disinfectants on alginate, polyether, and polyvinyl siloxane impression materials. Int J Prosthodont. 2007;20(3):299-307.

20. Ginjupalli K, Alla RK, Tellapragada C, Gupta L, Upadhya Perampalli N. Antimicrobial activity and properties of irreversible hydrocolloid impression materials incorporated with silver nanoparticles. $J$ Prosthet Dent. 2016;115(6):722-8.

21. Benakatti VB, Patil AP, Sajjanar J, Shetye SS, Amasi UN, Patil R. Evaluation of Antibacterial Effect and Dimensional Stability of Self-disinfecting Irreversible Hydrocolloid: An in vitro Study. J Contemp Dent Pract. 2017;18(10):887-92.

22. Storer R, McCabe JF. An investigation of methods available for sterilising impressions. Br Dent J. 1981;151(7):217-9.

23. Durr DP, Novak EV. Dimensional stability of alginate impressions immersed in disinfecting solutions. ASDC J Dent Child. 1987;54(1):45-8.

24. Rentzia A, Coleman DC, O'Donnell MJ, Dowling AH, O'Sullivan M. Disinfection procedures: their efficacy and effect on dimensional accuracy and surface quality of an irreversible hydrocolloid impression material. J Dent. 2011;39(2):133-40.

25. Taylor RL, Wright PS, Maryan C. Disinfection procedures: their effect on the dimensional accuracy and surface quality of irreversible hydrocolloid impression materials and gypsum casts. Dent Mater. 2002;18(2):103-10.

26. Hiraguchi $H$, Kaketani $M$, Hirose $H$, Yoneyama T. The influence of storing alginate impressions sprayed with disinfectant on dimensional accuracy and deformation of maxillary edentulous stone models. Dent Mater J. 2010;29(3):309-15.

27. Hasan Ö. Gümüş MD, Süleyman K, Büyük, Halil İ, Kılınç, Mehmet S, Bilgin M, Zortuk. The effect of pouring time on the dimensional stability of casts made from conventional and extended-pour irreversible hydrocolloids by 3D modelling. Journal of Dental Sciences. 2015;10(3):275-81.

28. Aalaei S, Ganj-Khanloo R, Gholami F. Effect of Storage Period on Dimensional Stability of Alginplus and Hydrogum 5. J Dent (Tehran). 2017;14(1):31-9.

29. Rohanian A, Ommati Shabestari G, Zeighami S, Samadi MJ, Shamshiri AR. Effect of storage time of extended-pour and conventional alginate impressions on dimensional accuracy of casts. J Dent (Tehran). 2014;11(6):655-64.

30. Owen CP. An investigation into the compatibility of some irreversible hydrocolloid impression materials and dental gypsum products. Part II. A refined discriminatory procedure. J Rehabil. 1986;13(2):147-62. 
31. Hamedi Rad F, Ghaffari T, Safavi SH. In vitro evaluation of dimensional stability of alginate impressions after disinfection by spray and immersion methods. J Dent Res Dent Clin Dent Prospects. 2010;4(4):130-5.

32. Ismail HA, Mahross HZ, Shikho S. Evaluation of dimensional accuracy for different complete edentulous impressions immersed in different disinfectant solutions. European journal of dentistry. 2017;11(2):242-9.

33. Doddamani S, Patil RA, Gangadhar SA. Efficacy of various spray disinfectants on irreversible hydrocolloid impression materials: an in vitro study. Indian J Dent Res. 2011;22(6):764-9.

\section{Figures}

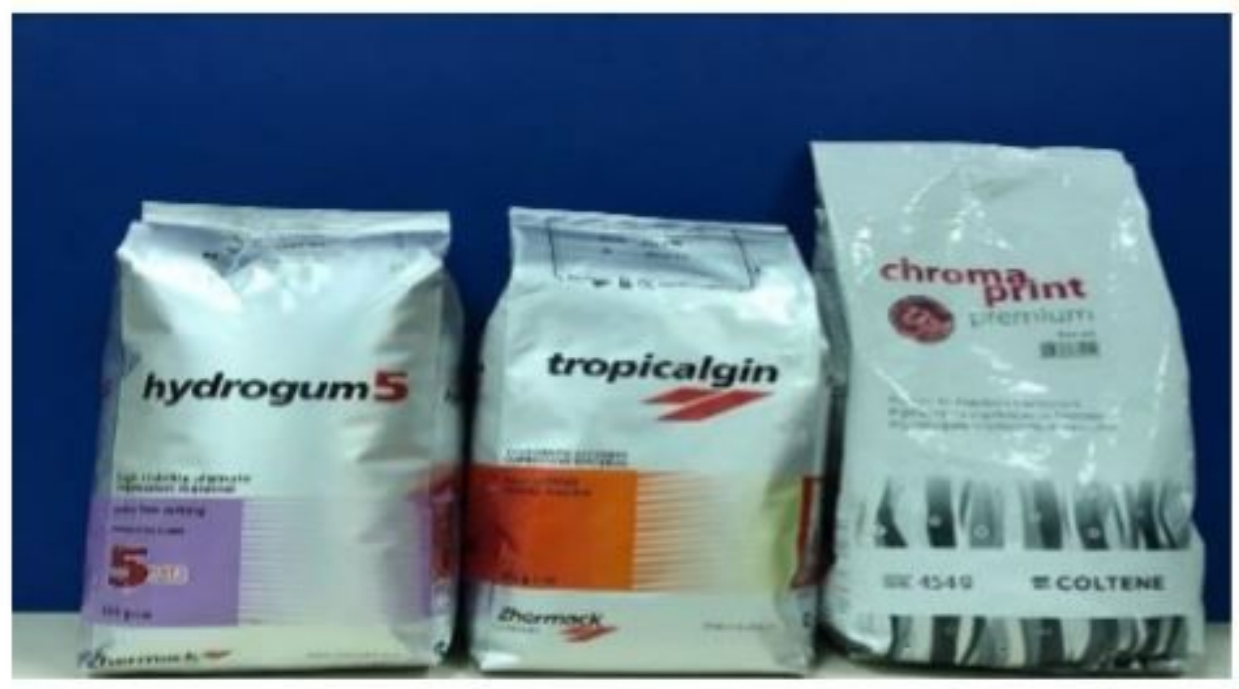

Figure 1

Different Alginate Impression Materials 

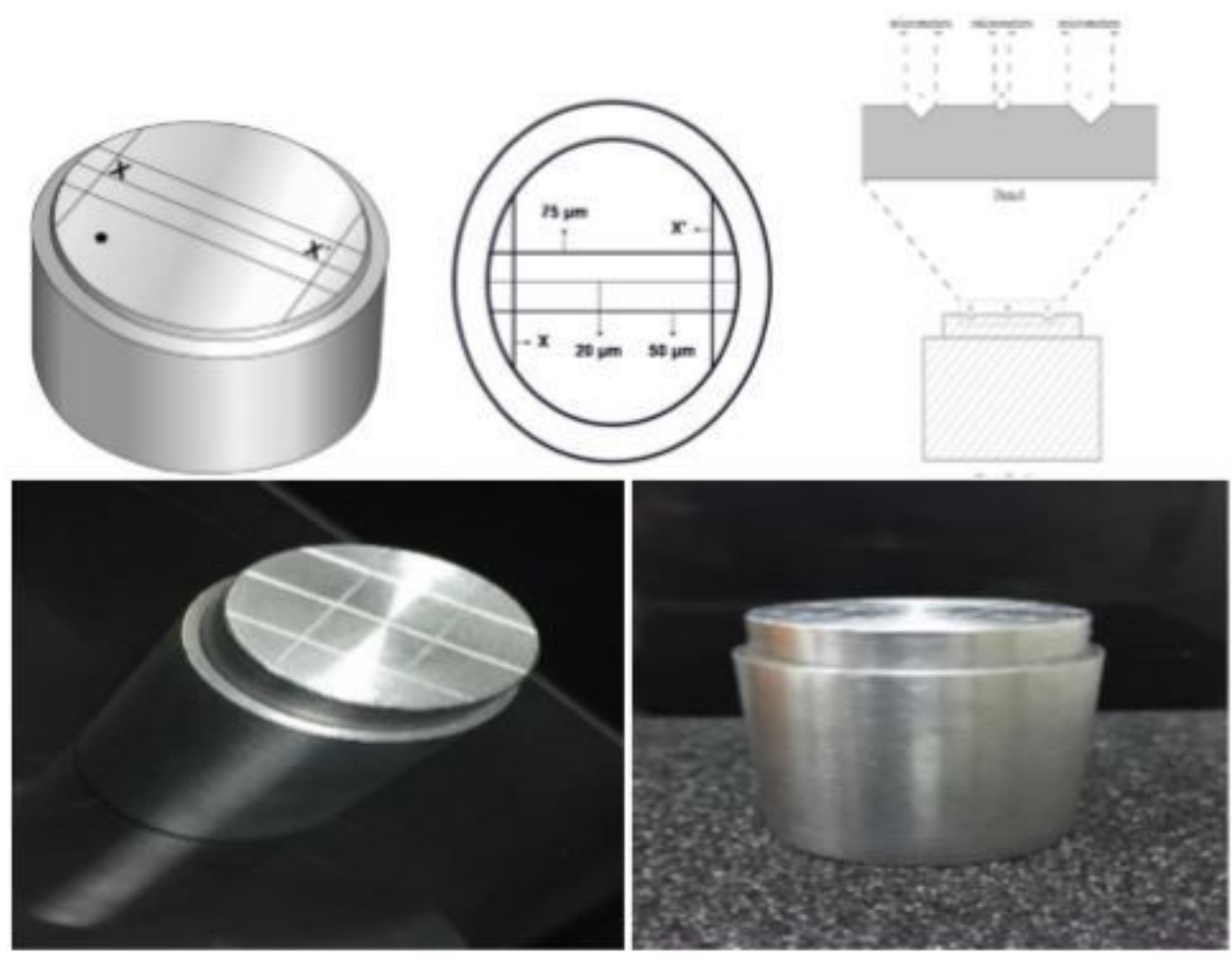

Figure 2

Custom stainless steel die used for making impression

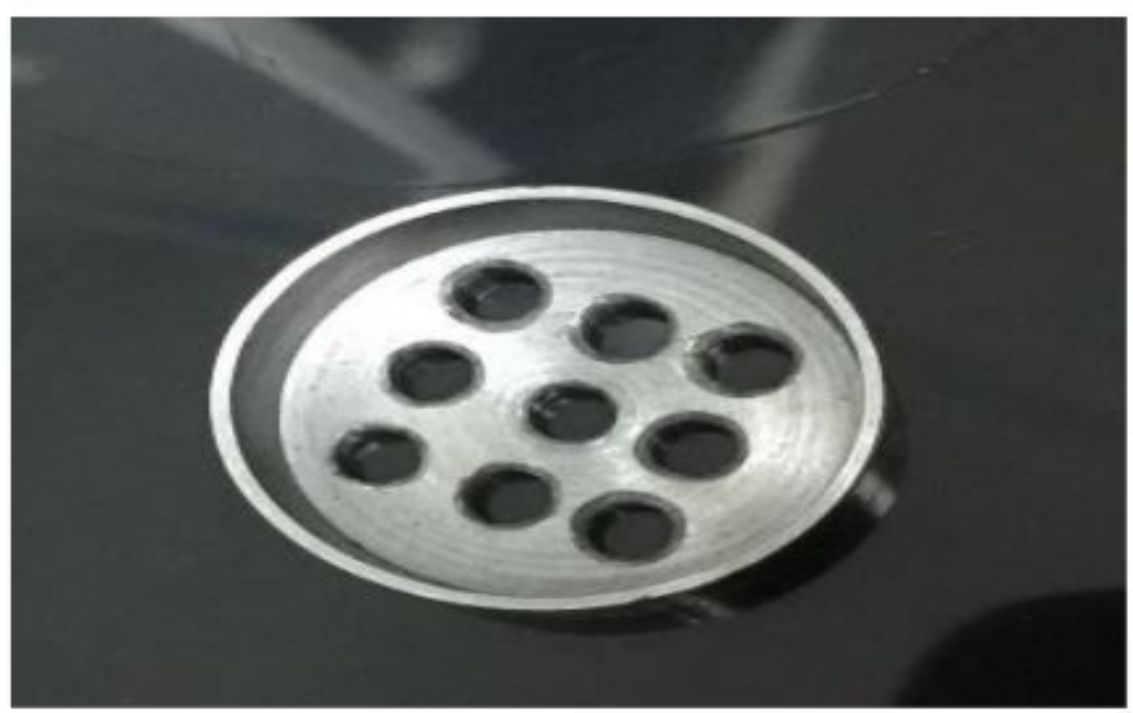

Figure 3

custom-made perforated metal tray 


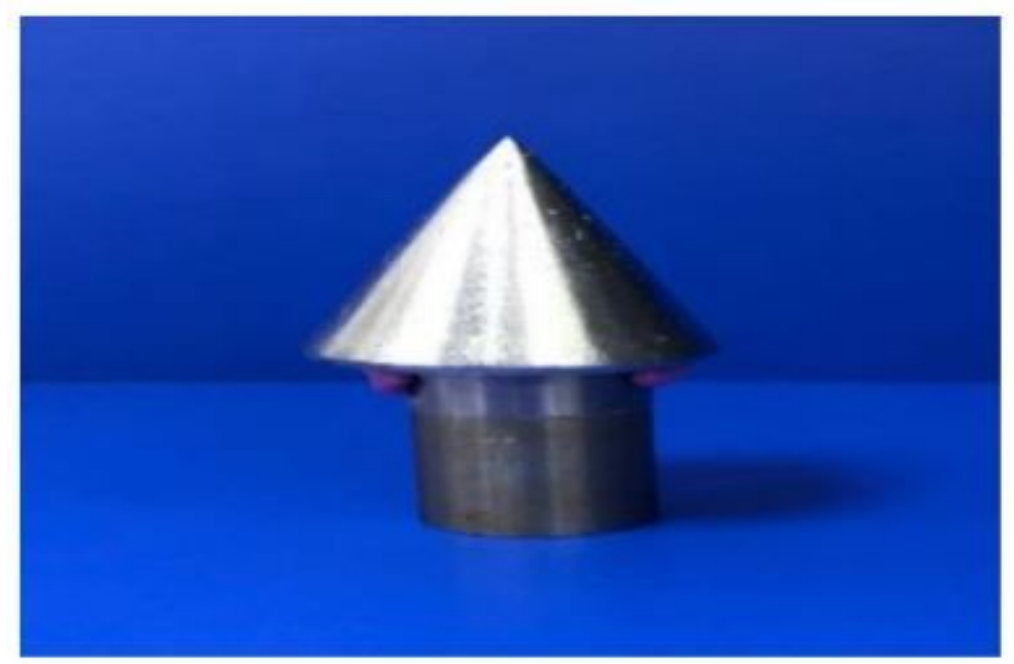

Figure 4

A $1 \mathrm{~kg}$ weight placed over the tray to allow even pressure

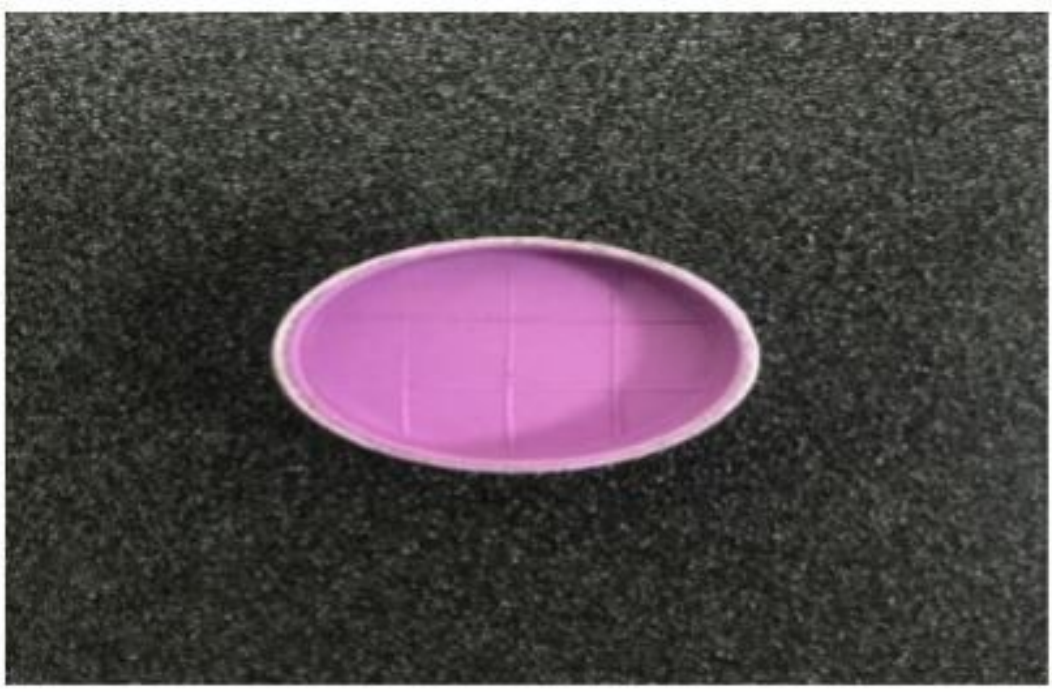

Figure 5

Completed impression 


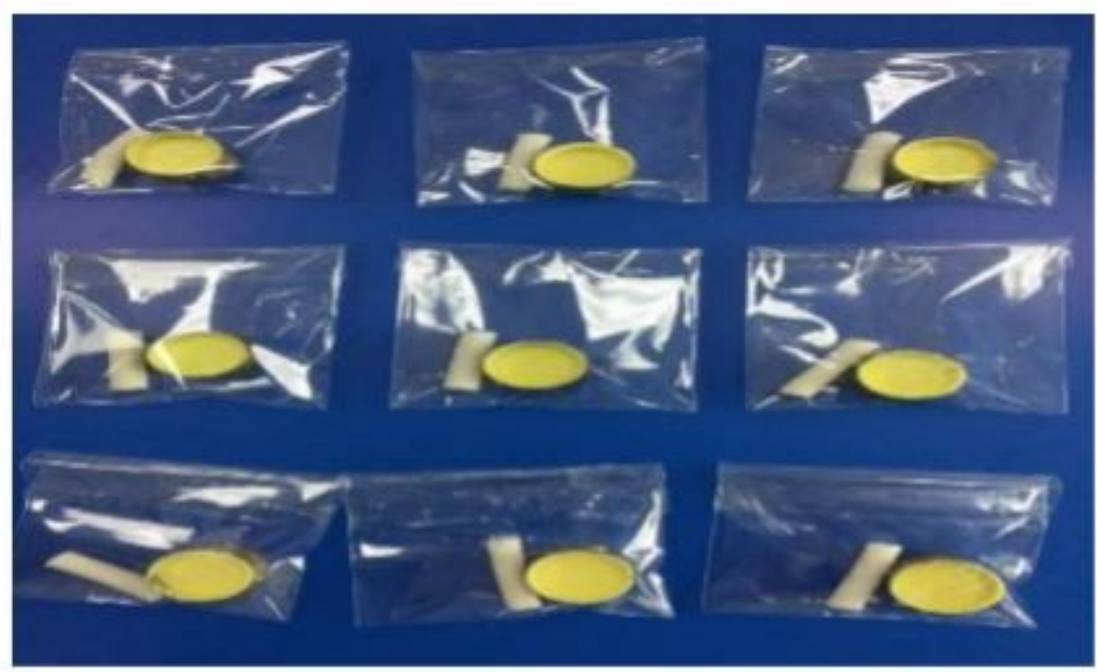

Figure 6

A group of stored impression samples

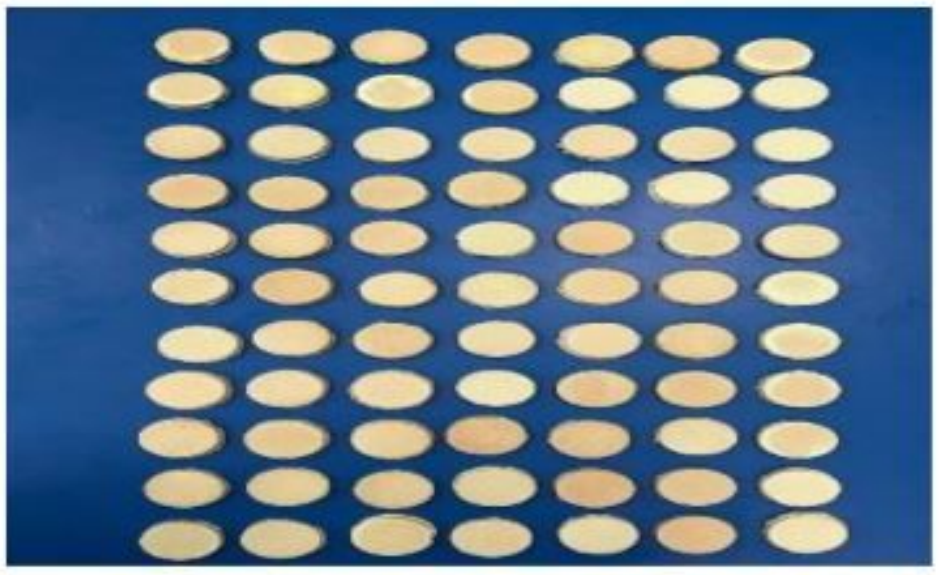

Figure 7

A group of poured casts

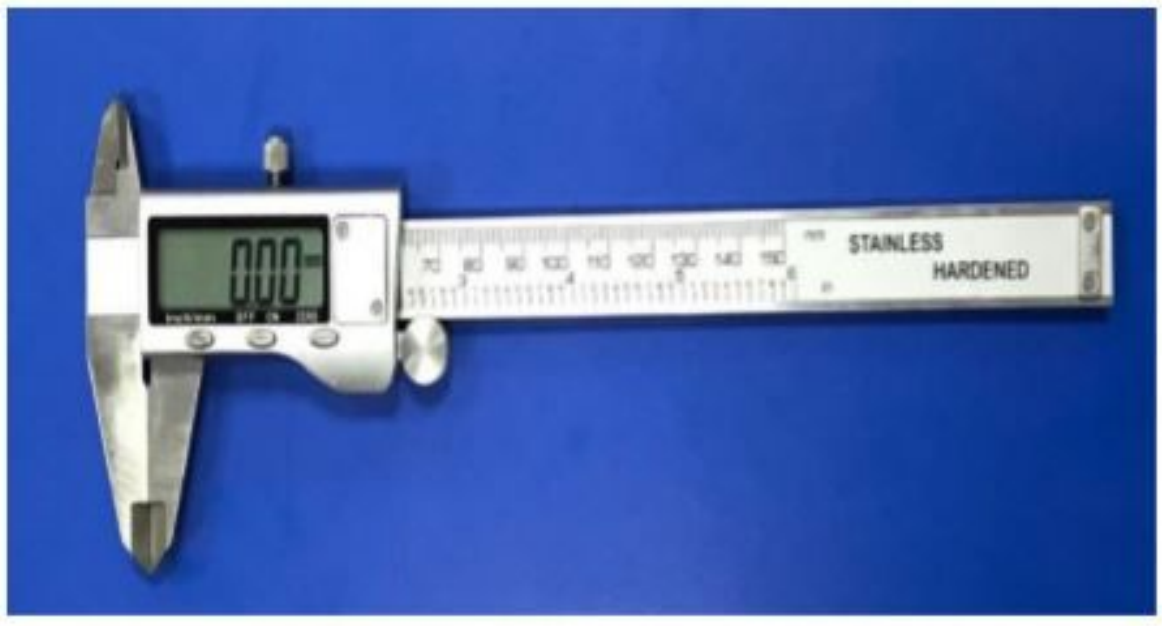


Figure 8

Electronic digital caliper used for measuring the dimensional changes.

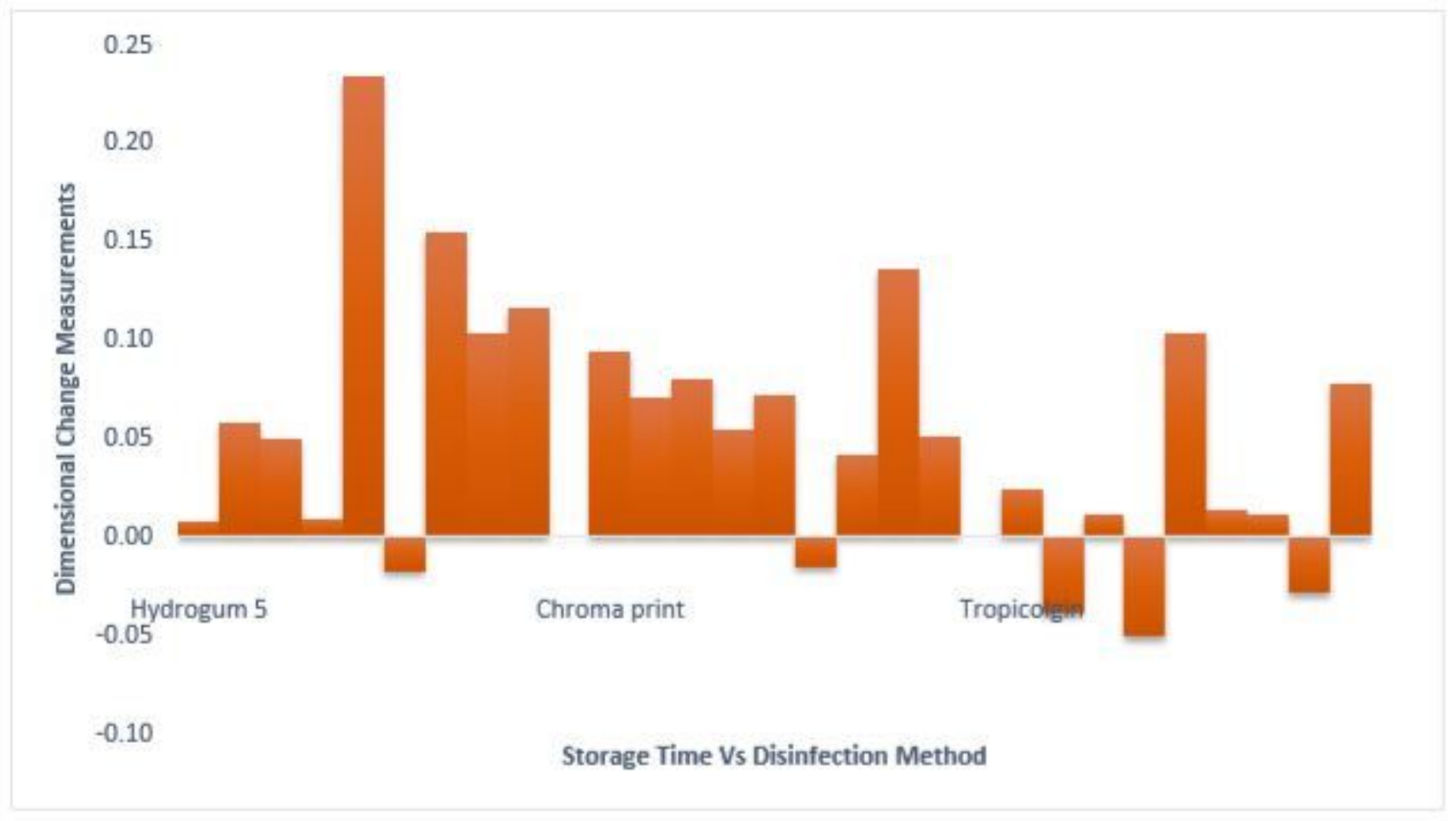

Figure 9

Dimensional Change of casts made from the 3 impression materials with different disinfection conditions and storage time interval

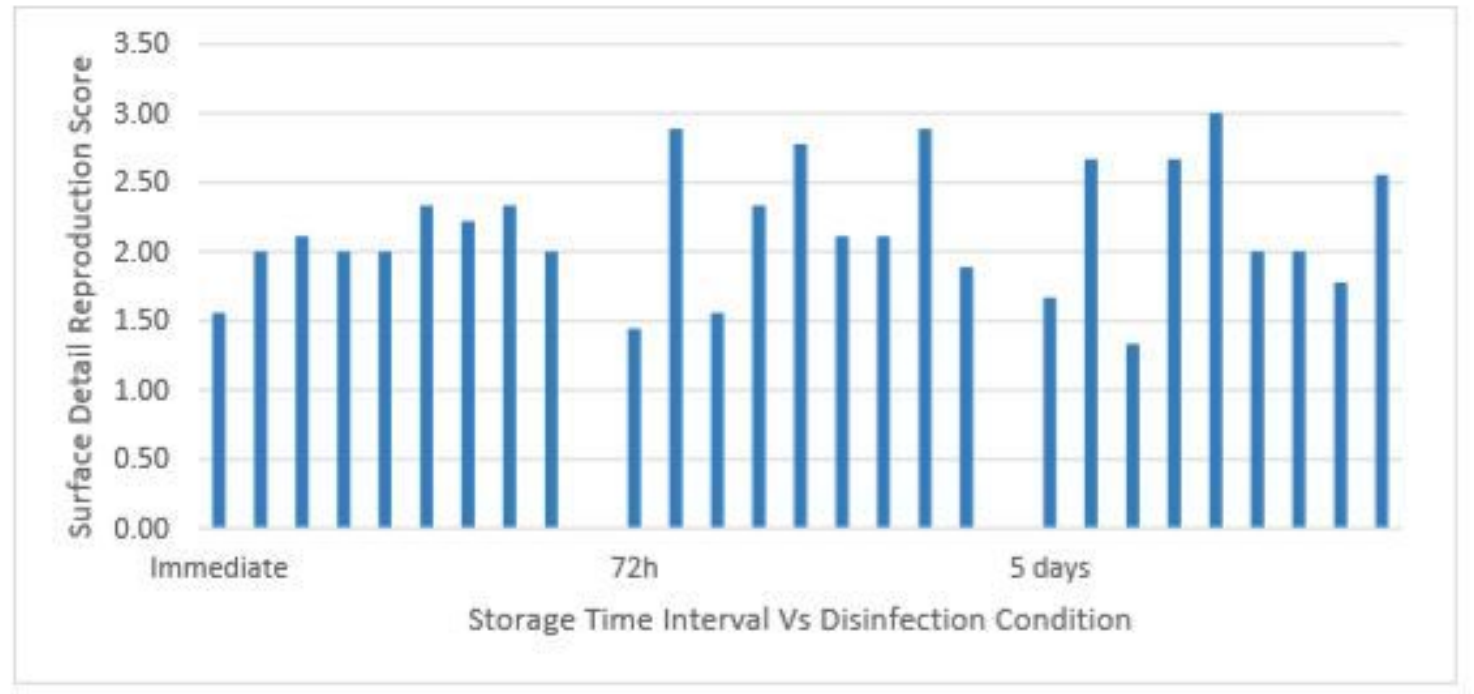

Figure 10

surface detail reproduction of all casts 


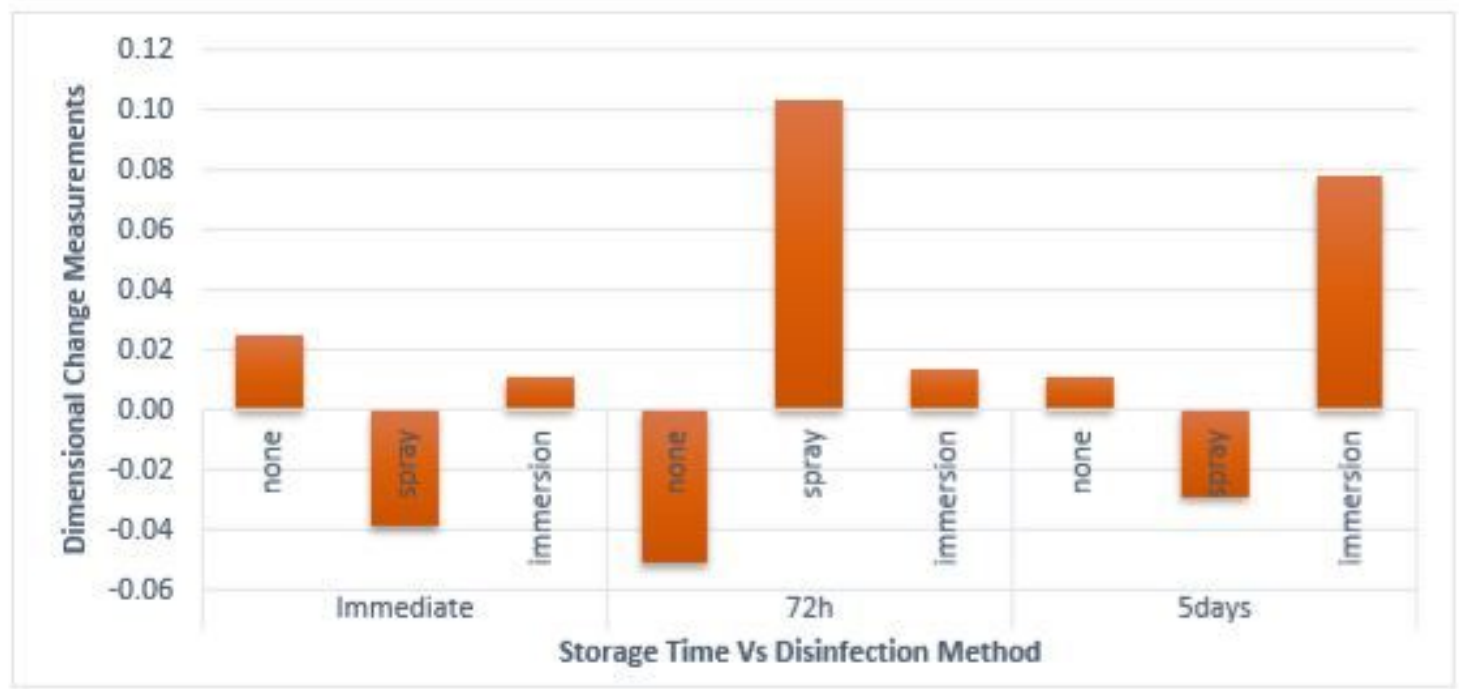

Figure 11

dimensional change of Tropicalgin

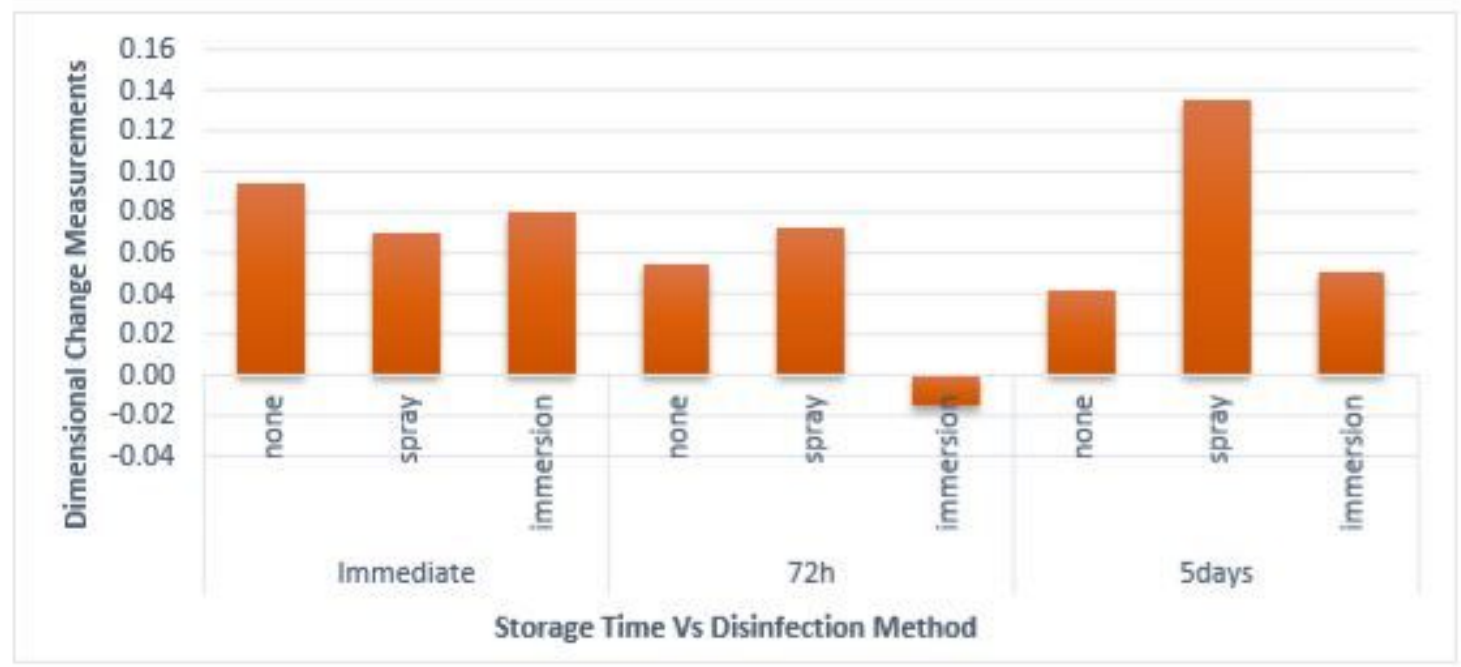

Figure 12

dimensional change of Chroma Print 


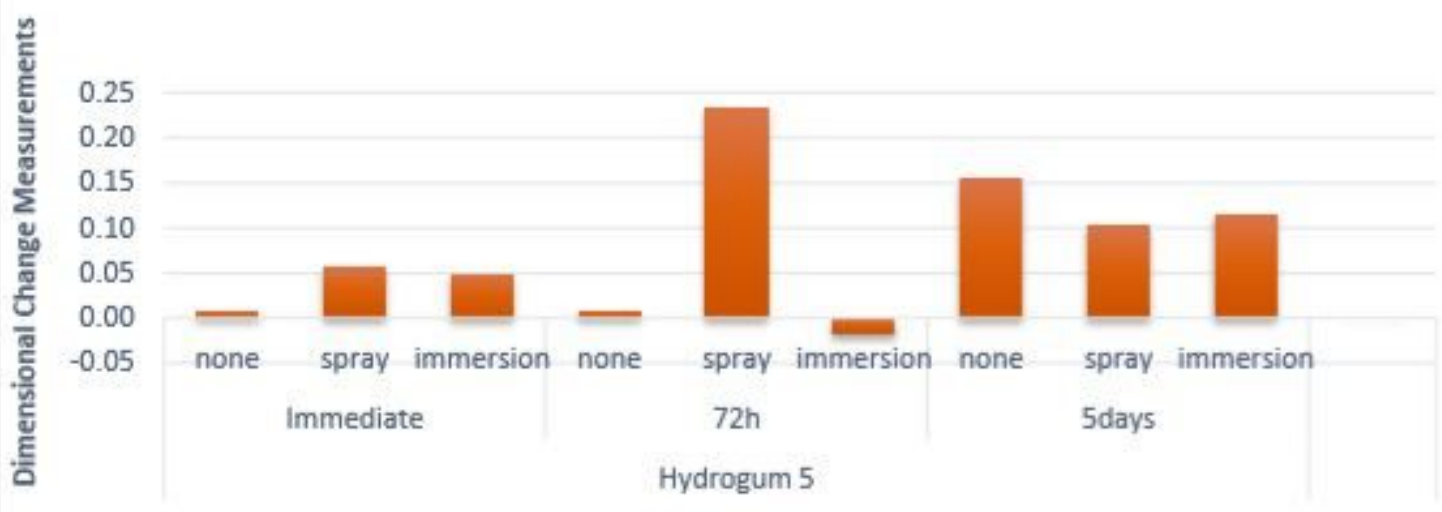

Storage Time Vs Disinfection Method

\section{Figure 13}

dimensional change of Hydrogum 5

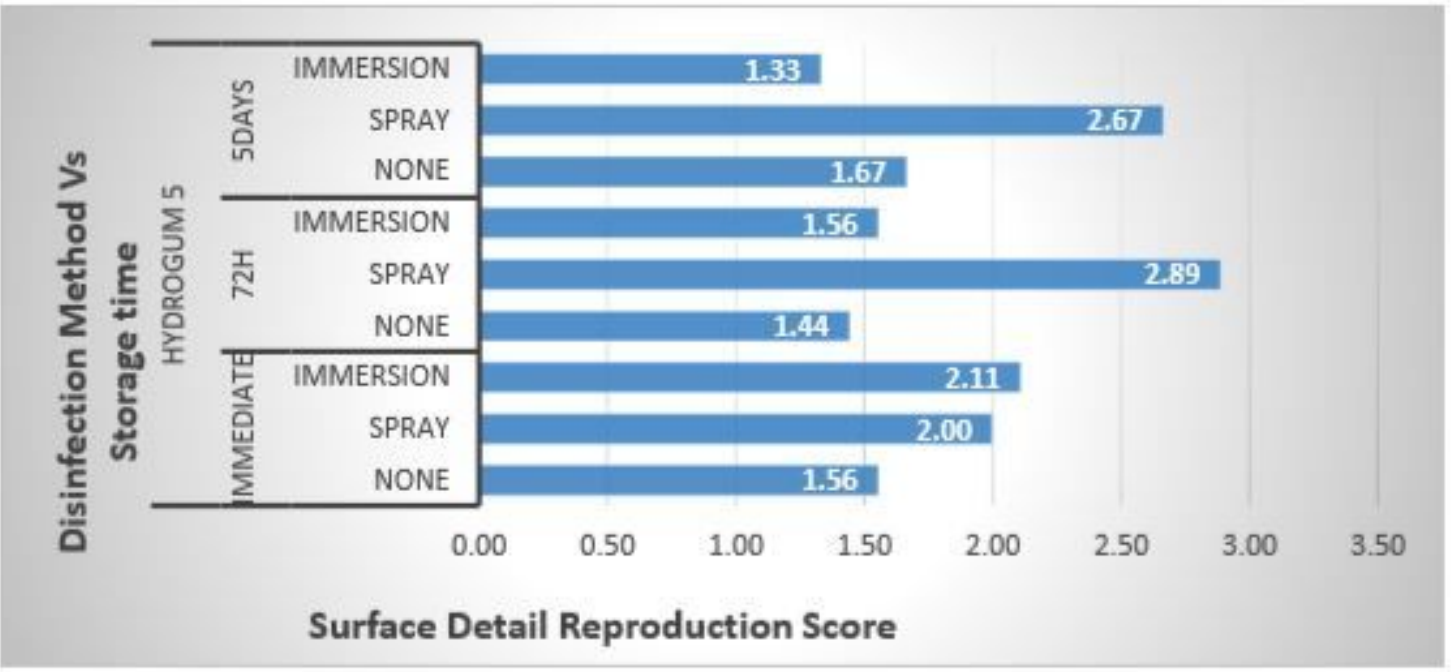

Figure 14

surface detail reproduction of Hydrogum 5 


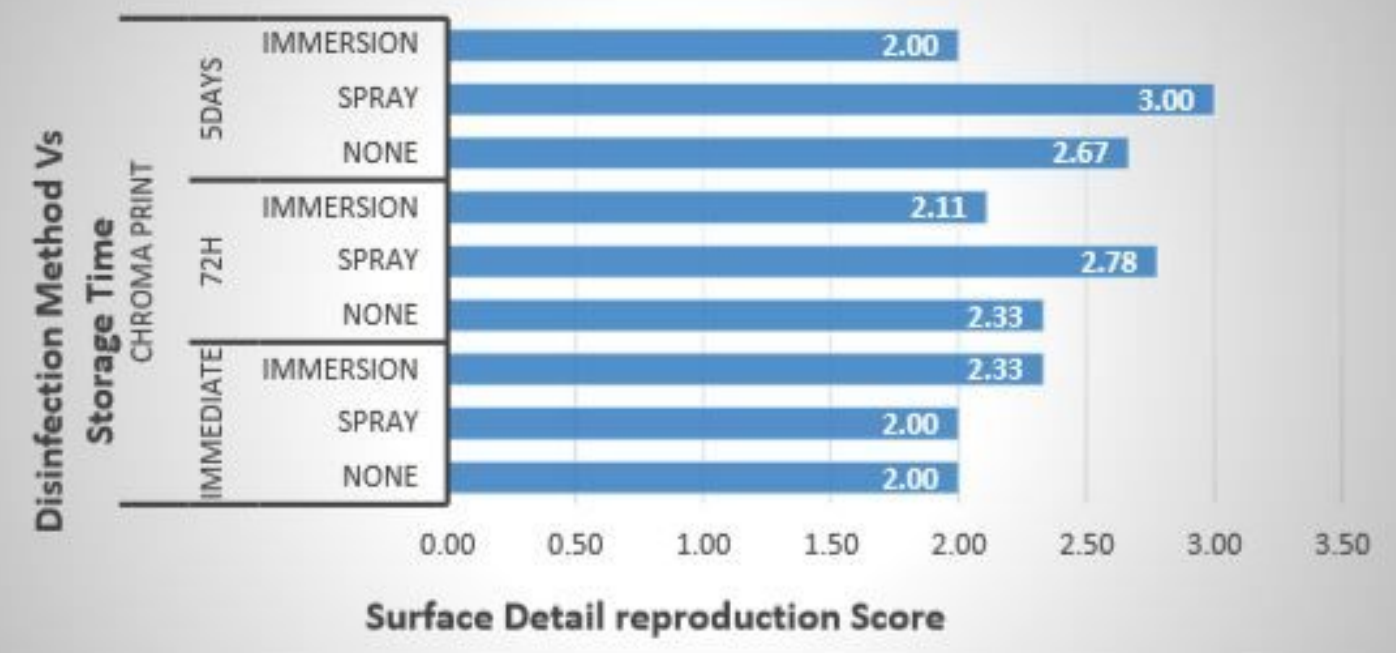

Figure 15

surface detail reproduction of chroma print

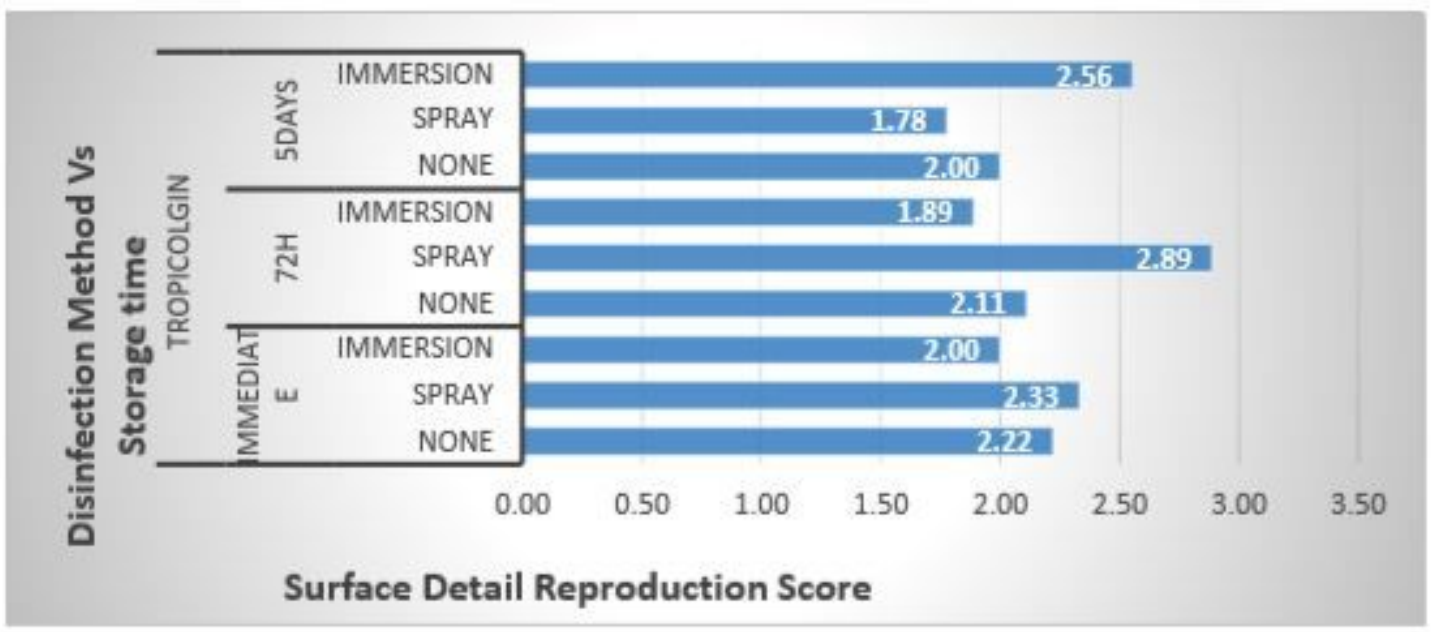

Figure 16

surface detail reproduction of Tropicalgin 


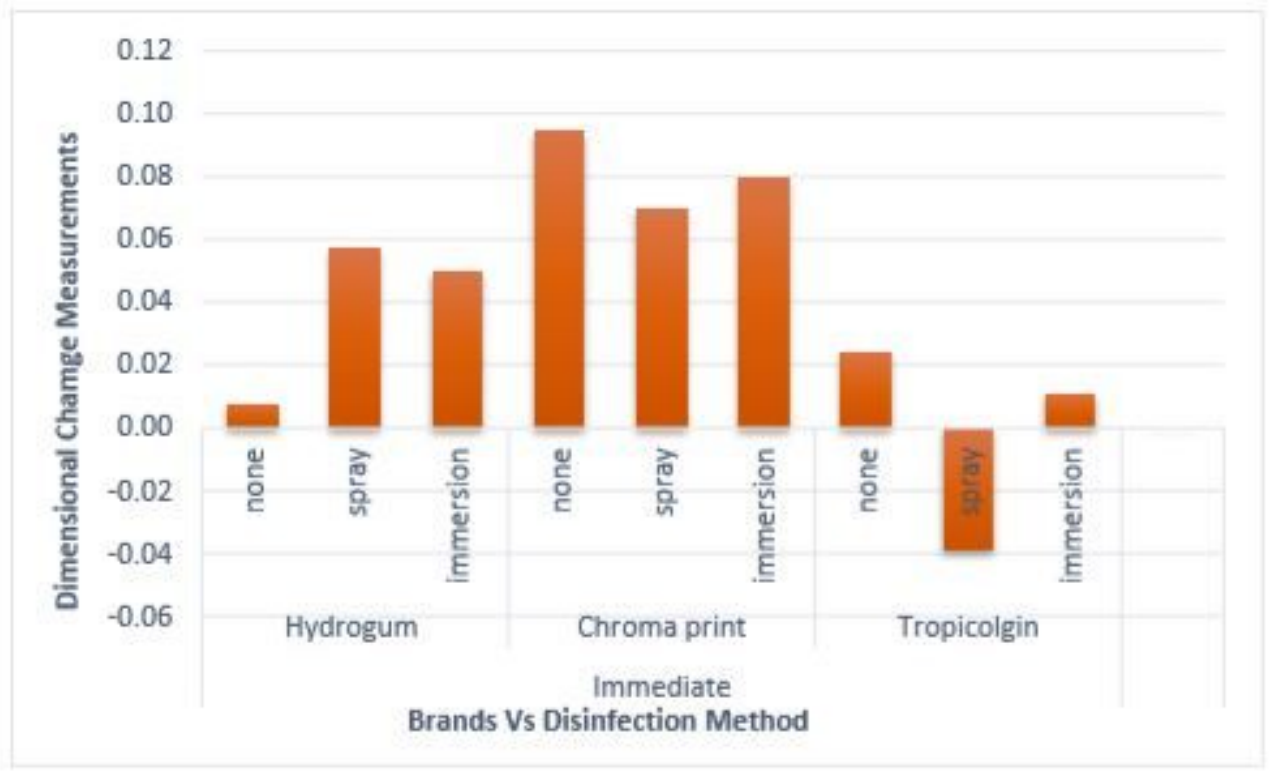

Figure 17

dimensional changes on immediate pouring

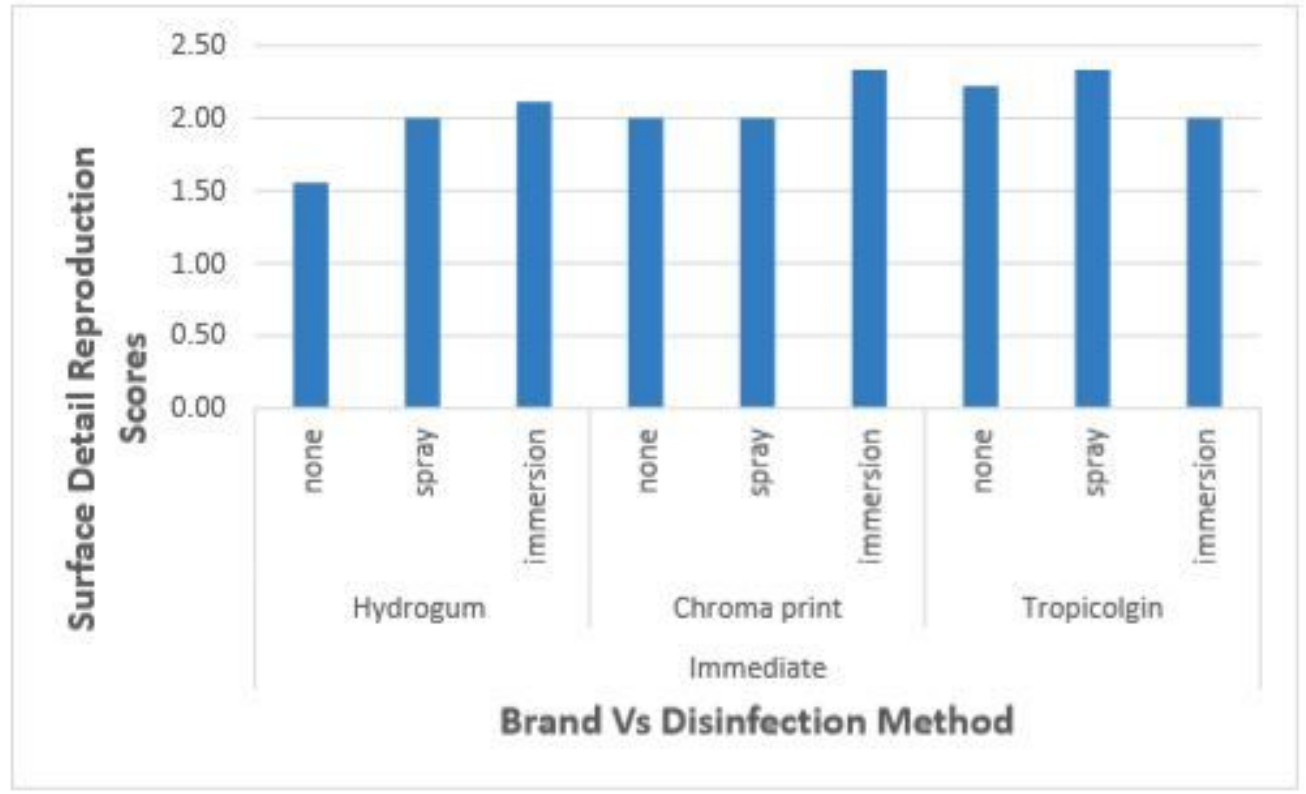

Figure 18

surface detail reproduction on immediate pouring 


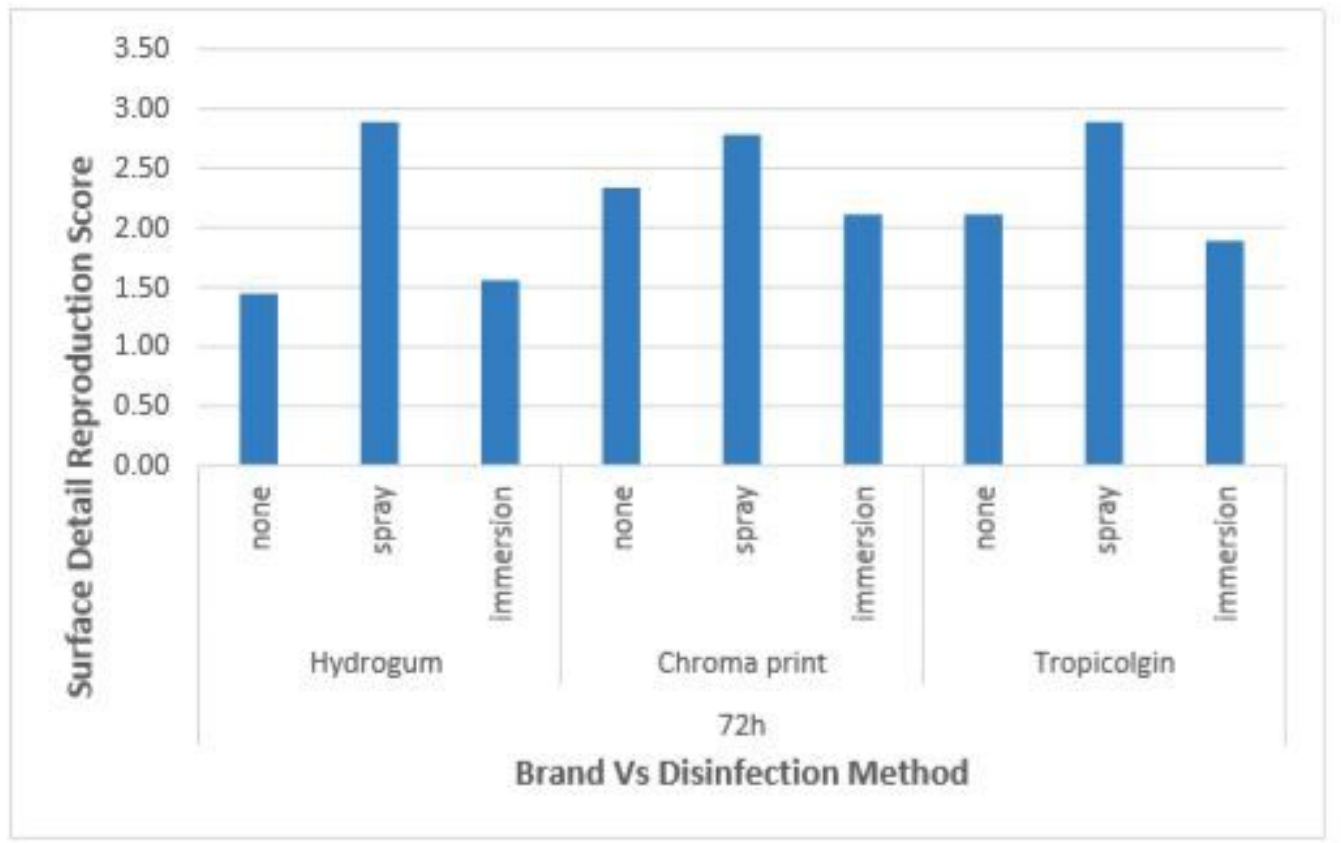

Figure 19

surface detail reproduction after 72 hours

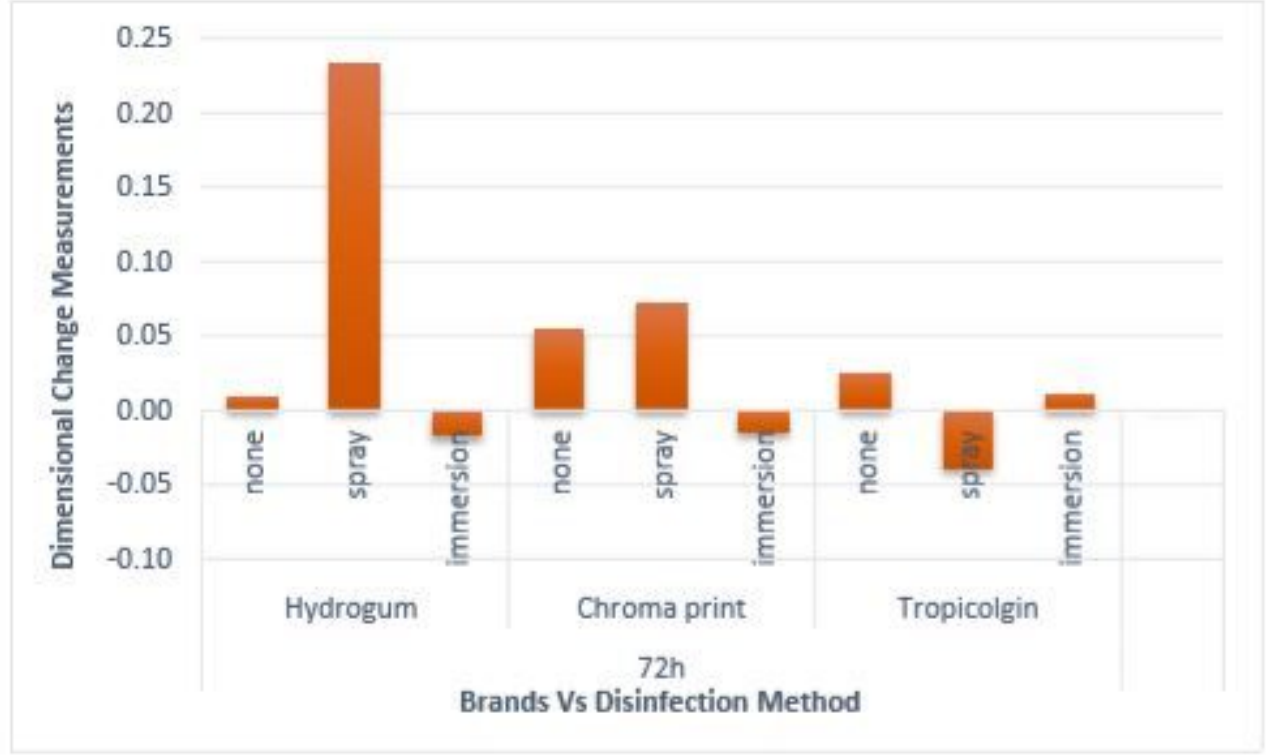

Figure 20

dimensional changes after 72 hours of storage 


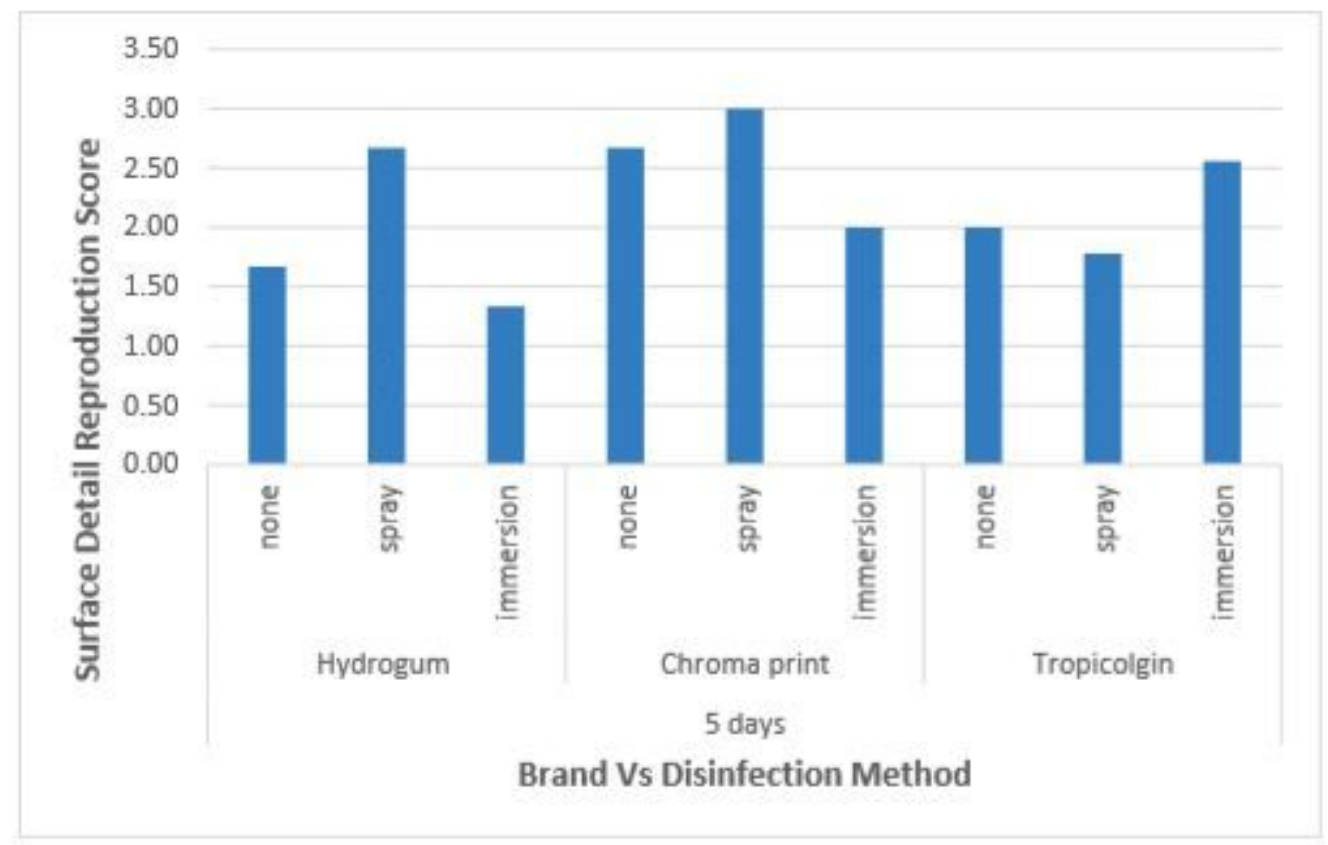

Figure 21

surface detail reproduction after 5 days

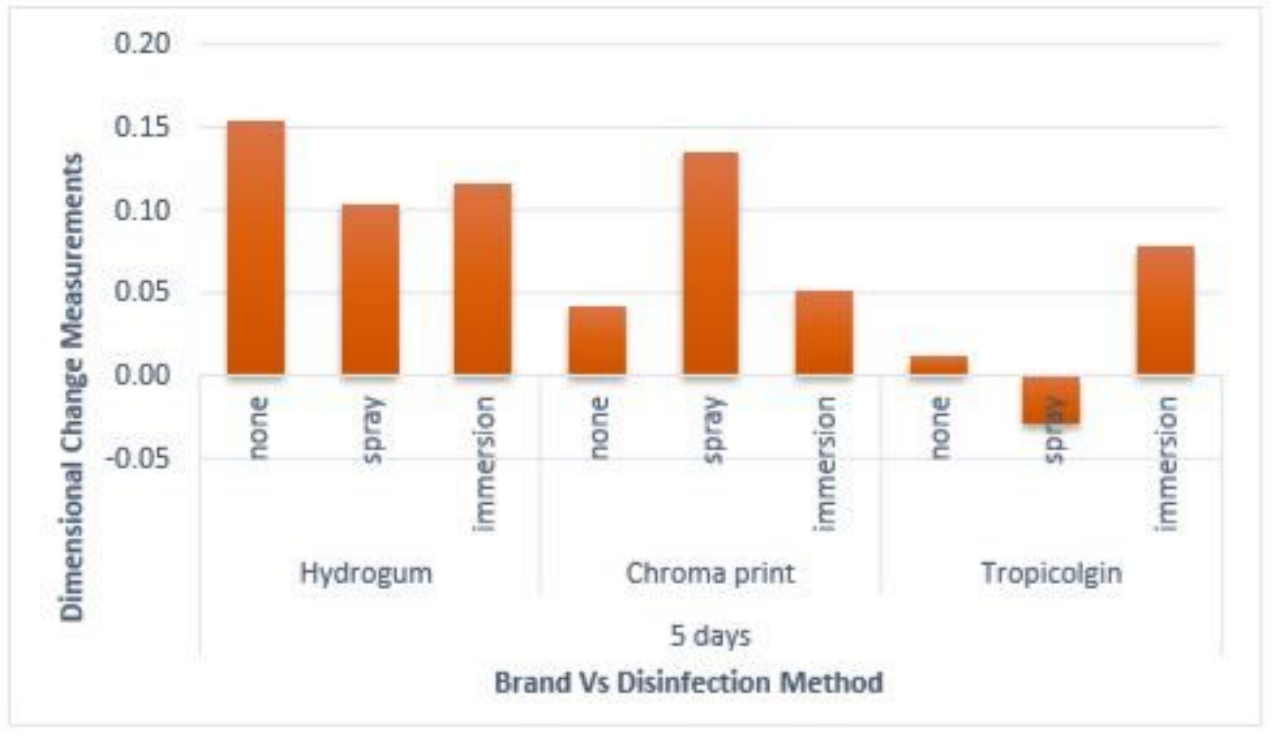

Figure 22

dimensional change after 5 days of storage 


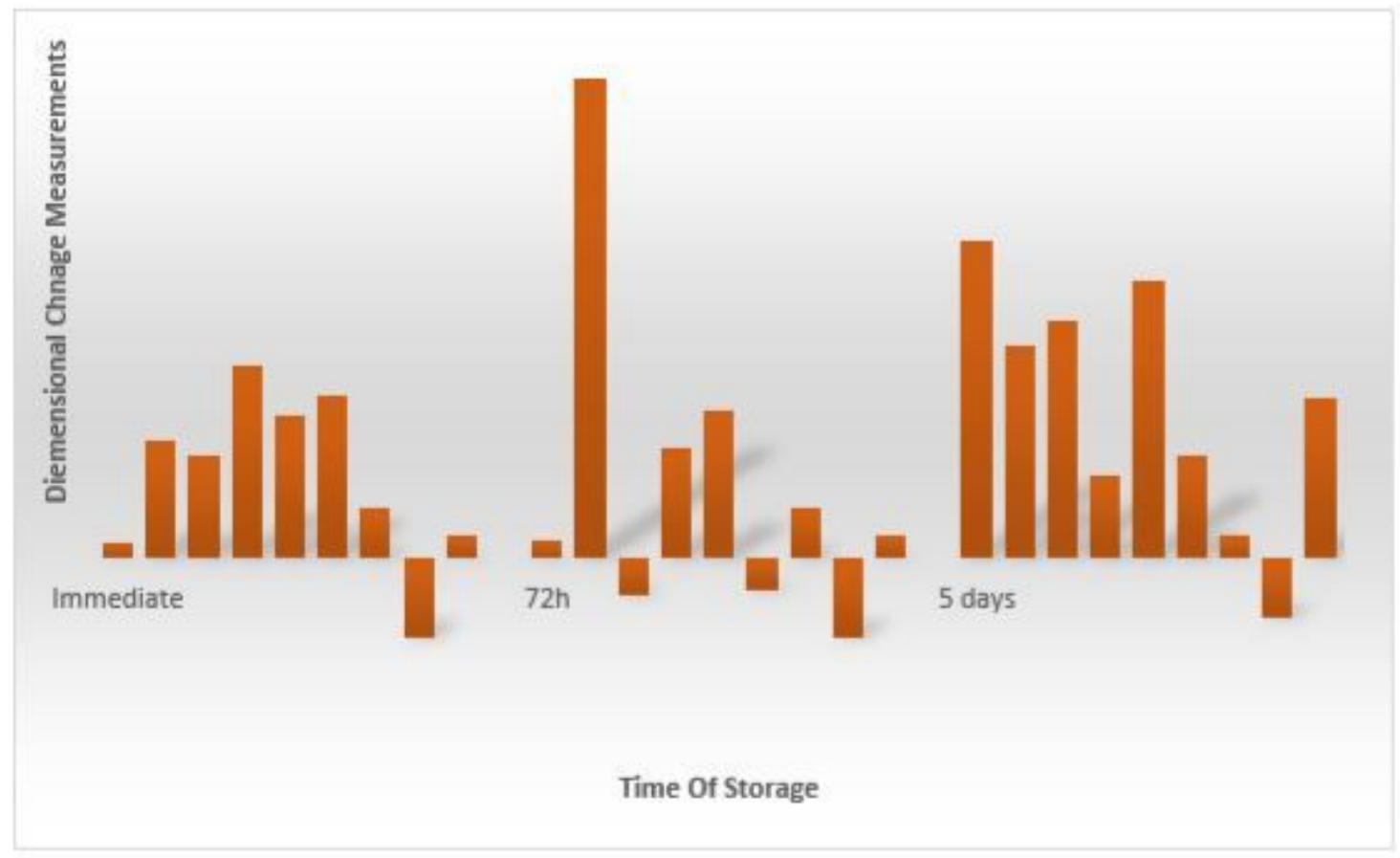

Figure 23

dimensional change of all casts at different storage time intervals 